REGARDS

SUR L'ECONOMIE ALLEMANDE

BULLETIN ECONOMIQUE DU CIRAC
Regards sur l'économie allemande

Bulletin économique du CIRAC

$102 \mid 2011$

Varia

\title{
Inégalités sociales
}

LAUTERBACH W., DRUYEN T., GRUNDMANN M., Vermögen in Deutschland - Heterogenität und Verantwortung / WILLKE G., Armut was ist das? Eine Grundsatzanalyse / BURZAN N., Soziale Ungleichheit Eine Einführung in die zentralen Theorien

\section{(2) OpenEdition}

\section{Journals}

Édition électronique

URL : http://journals.openedition.org/rea/4337

DOI : $10.4000 /$ rea. 4337

ISBN : 978-2-8218-1134-8

ISSN : 1965-0787

Éditeur

CIRAC

Édition imprimée

Date de publication : 31 octobre 2011

ISSN : 1156-8992

Référence électronique

"Inégalités sociales », Regards sur l'économie allemande [En ligne], 102 | octobre 2011, mis en ligne le 04 novembre 2011, consulté le 22 septembre 2020. URL : http://journals.openedition.org/rea/4337 ; DOI : https://doi.org/10.4000/rea.4337

Ce document a été généré automatiquement le 22 septembre 2020.

(c) CIRAC 


\section{Inégalités sociales}

LAUTERBACH W., DRUYEN T., GRUNDMANN M., Vermögen in Deutschland - Heterogenität und Verantwortung / WILLKE G., Armut was ist das? Eine Grundsatzanalyse / BURZAN N., Soziale Ungleichheit Eine Einführung in die zentralen Theorien 


\section{RÉFÉRENCE}

LAUTERBACH W., DRUYEN T., GRUNDMANN M., Vermögen in Deutschland -

Heterogenität und Verantwortung, VS Verlag, Wiesbaden, 2011, 224 p.

WILLKE G., Armut - was ist das? Eine Grundsatzanalyse, Murmann, Hambourg, 2011, $260 \mathrm{p}$.

BURZAN N., Soziale Ungleichheit - Eine Einführung in die zentralen Theorien, 4.

Auflage, VS Verlag, Wiesbaden, 2011, 204 p.

Outre-Rhin, les débats actuels font état d'une fonte des classes moyennes et d'une tendance à la polarisation de la société. Voici trois ouvrages offrant la possibilité d'approfondir la thématique, sous l'angle de la richesse, de la pauvreté et des inégalités sociales. Sur la base d'une enquête réalisée auprès de 500 ménages aisés, le premier (LAUTERBACH et al.) place le curseur sur la responsabilité sociale des personnes fortunées et sur l'évolution de la recherche en matière de richesse, de patrimoine et de culture du patrimoine. A l'autre bout du spectre, Gerhard WILKE se penche de manière critique sur le concept de pauvreté, ses représentations au fil de l'histoire, les formes et la mesure de la pauvreté et les politiques menées pour la combattre. A lire absolument pour distinguer entre ce qui, dans la relation que font les médias des diverses statistiques ou prises de position sur la pauvreté, relève de l'imprécision, voire de l'idéologie, ou à l'inverse d'un constat factuel. Maîtriser les concepts permet de ne pas tomber dans l'amalgame et d'affronter objectivement la réalité. Nicole BURZAN aussi voue son ouvrage aux Lumières : elle s'attelle pour sa part à clarifier le concept même d'inégalité sociale, via un examen précis des théories, anciennes et modernes, des classes sociales. (sh) 